
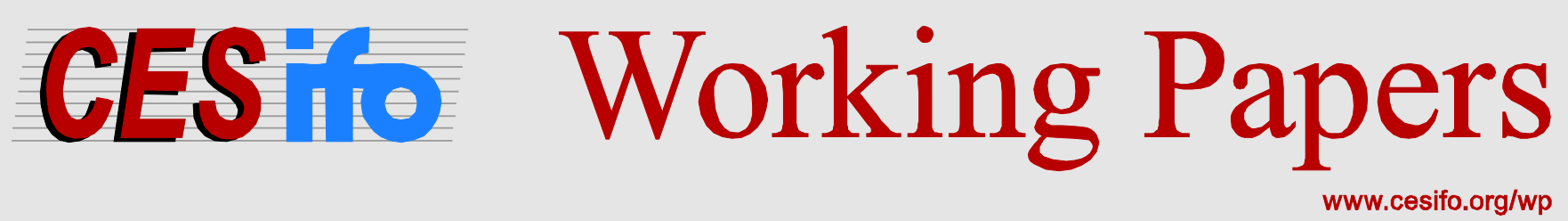

\title{
The Effectiveness of Taxing Carbon Content of Energy Consumption
}

\author{
Suphi Sen \\ Herman Vollebergh
}

\author{
CESIFO WORKING PAPER NO. 6003 \\ CATEGORY 10: ENERGY AND CLIMATE ECONOMICS \\ JULY 2016
}

An electronic version of the paper may be downloaded

- from the SSRN website:

- from the RePEc website:

- from the CESifo website:

WwW.SSRN.com

Www.RePEc.org

www.CESifo-group.org/wp 


\title{
The Effectiveness of Taxing Carbon Content of Energy Consumption
}

\begin{abstract}
We estimate the long-run effect of a uniform carbon tax on energy consumption by using a new and unique dataset in which effective tax rates of OECD countries are calculated in terms of carbon dioxide emissions. The effective tax rates account for the widely discussed tax deductions for specific energy tax bases leading to a careful calculation of net tax rates faced by agents. We argue that taxation might be endogenous to energy consumption in the long run. In order to identify a causal effect, we document a positive correlation between the tax rates of neighboring countries which we then exploit in our instrumental variables estimations. Validity of our identification strategy is consistent with the strategic inter-governmental interaction theories that lead to a spatial pattern in local government policies in the presence of immobile tax bases. Our instrumental variables estimations indicate that taxing carbon content of energy use can be an effective instrument for climate policy.
\end{abstract}

JEL-Codes: Q410, Q480, H230, C260.

Keywords: effective tax rates, energy taxation, energy consumption, carbon-dioxide emissions, IV estimation.

Suphi Sen

Ifo Institute - Leibniz Institute for

Economic Research

at the University of Munich

Poschingerstrasse 5

Germany-81679 Munich

sen@ifo.de
Herman Vollebergh

Netherlands Environmental

Assessment Agency

P.O. Box 303

The Netherlands - 3720 AH Bilthoven

herman.vollebergh@pbl.nl

We thank Michelle Harding, Hendrik Vrijburg, Jan Brueckner, Erdal Aydin, David Rapson, Bertrand Melenberg, Reyer Gerlagh, Malik Curuk, Gabriel Felbermayr, Michele Battisti, Ron Steenblik, Kurt van Dender, the participants of the EAERE conference in Zurich, and the participants of various seminars at the OECD and Ifo for their insightful suggestions. 


\section{Introduction}

Facing the challenge to reduce $\mathrm{CO}_{2}$ emissions worldwide in order to limit the increase in the global mean temperature to at most $2^{\circ} \mathrm{C}$ above pre-industrial levels, countries should shift towards a carbon emission reduction pathway. Carbon pricing is widely considered the most important policy instrument providing a cost effective mechanism for governments to induce such a transition. One obvious and simple way to price carbon is a (global) tax on carbon (Metcalf, 2009; Parry et al., 2012; Weitzman, 2016). Indeed, some countries have already introduced direct or indirect carbon taxation along with existing energy taxes, such as in Norway where more than half of the $\mathrm{CO}_{2}$ emissions are covered by such a tax scheme, or as in the Netherlands which covers most of its highly fossil fuel-intensive economy through an implicit carbon tax.

As the energy consumption accounts for more than two-thirds of global $\mathrm{CO}_{2}$ emissions, taxing energy use, in particular if levied on fossil fuels, implicitly raises the shadow price of these polluting energy resources and can send significant price signals that may influence energy consumption patterns. Therefore, taxing carbon content of energy consumption is considered a key strategy to price emissions (Vollebergh, 2012; Parry et al., 2012). Metcalf (2009) argues that taxing carbon content of oil, natural gas, and coal is a simple and cost effective strategy also from an administrative perspective. However, energy consumption is considered not to be very sensitive to price and hence to tax changes. Therefore, a priori, it is not clear whether taxing the carbon content of energy use is an effective strategy or not.

Remarkably little is known on the effectiveness of taxing the carbon content of energy consumption. In general, the existing literature either focus on one sector, in particular gasoline demand, and use energy prices as a proxy for energy taxes. ${ }^{1}$ First, the limitation to one sector has clearly little to offer for understanding economy wide impacts of a broad based carbon tax on all fossil fuels, in particular also on the electricity generating sector. Second, a

\footnotetext{
${ }^{1}$ Dahl and Sterner (1991) and Espey (1998) presents extensive surveys of this literature. More recently, Brons et al. (2008) presents a meta-analysis based on seemingly unrelated regressions (SUR) approach.
} 
tax is likely to have a different impact than a change in fossil fuel prices. $^{2}$ Taking these shortcomings into account, this paper investigates the average effectiveness of a uniform increase in energy taxes levied on the carbon content of energy use by specific tax bases covering the entire energy tax base.

Until recently it has also been rather difficult to study the impact of carbon or energy taxation across countries due to a lack of reliable dataset. In this paper, we exploit a new and unique cross-sectional dataset in which the energy tax base and the effective energy taxes of OECD countries are measured in $\mathrm{CO}_{2}$ content of energy consumption across different energy use ${ }^{3}$ and resource categories. Our dataset includes calculated effective tax rates which accounts for the tax concessions prevalent in the energy market. These are the true tax rates that the agents face. In the OECD countries, the preponderance of the support in the energy market are in the form of reduced tax rates, rather than direct price subsidies (OECD, 2013a). Therefore, the nominal and effective energy tax rates differ substantially (see Ekins and Speck 1999 for a detailed discussion). Using nominal rates instead of effective taxes might lead to misleading conclusions due to the additional variation from ignoring the tax concessions. Another important advantage of our dataset is that it is comparable across energy use and resource categories, hence we are able to control for resource, user, and country specific effects by introducing related dummies, and even their interactions. This extensive set of controls reduce the concerns about omitted variables bias by leaving a very specific variation to be exploited.

Estimates of the effect of energy taxes on energy use potentially suffer from an endogeneity problem which often goes unrecognized in the literature. The recent literature has raised another identification problem in estimating the price elasticity of the energy resource consumption. Highlighting the lack of any study, Davis and Kilian (2011) estimate the effect of gasoline prices on

\footnotetext{
${ }^{2}$ For example, according to Davis and Kilian (2011), this might be due to the fact that changes in tax rates are more persistent than the price changes. Li et al. (2014) propose a functional specification to separate out the price and the tax effects. Their findings are consistent with the intuition in Davis and Kilian (2011).

${ }^{3}$ Throughout the paper "use category" and "sector" are used interchangeably.
} 
gasoline consumption by instrumenting the price changes with the tax changes. Their reason for employing an IV approach is the endogeneity problem inherent in estimating demand equations which is a well-known simultaneity problem. As in Davis and Kilian (2011), tax rates are generally taken to be exogenous in demand estimations. For example, investigating cigarette demand, Adda and Cornaglia (2006) use taxes instead of prices since the later is clearly endogeneous. In this paper, we argue that exogeneity of taxes to demand should not be taken as granted. Other than potential omitted variables, governments may set tax rates depending on the economic conditions leading to heterogeneous impacts across the tax base categories. In other words, government preferences over the energy taxes might be a function of the size of the energy tax base or some unobserved characteristics of the tax base. ${ }^{4}$ Endogeneity of policy is likely to be a long-run concern due to the fact that the state reaction to economic conditions might take place with considerable lags. In the current paper we exploit cross-sectional variation leading to long-run estimates of tax effectiveness. Therefore, in our case, this seems to be a valid concern. However, this problem has implications also for the panel data estimation techniques that are employed to estimate short-run effects. In particular, such a concern requires to control for feedback effects, ie. by employing a dynamic specification.

As the base to our main identification strategy to deal with the potential endogeneity of taxation, we document a positive correlation between the tax rates of neighboring countries, which is in line with the strategic policy interaction models. This is an interesting finding as it stands, since there are few empirical studies investigating policy convergence in energy resource markets. However, our main purpose is not to uncover the underlying causal mechanism leading to this result, but rather to exploit this correlation as an instrument to identify the causal effect of a carbon tax on energy consumption. Hence, in a two stage least squares (2SLS) estimation, it suffices that the energy consumption of a country is not directly related to neighboring countries' energy

\footnotetext{
${ }^{4}$ This has long been recognized in the literature on optimal tax theory. See Mankiw et al. (2009) for a recent discussion.
} 
tax rates. Exogeneity of this source variation is consistent with the prominent theories in the literature predicting a spatial pattern in government policies related to immobile tax bases such as yardstick competition or expenditure spillover models.

Our instrumental variables (IV) estimations indicate that a 1 Euro increase in the energy taxes, levied on tonnes of $\mathrm{CO}_{2}$, reduces $\mathrm{CO}_{2}$ emissions from energy consumption by 0.73 percent in the long-run, which implies an average elasticity of 0.3 . This result suggests that energy taxation can be an effective tool for countries to achieve the goal of reducing $\mathrm{CO}_{2}$ emissions. This result is robust to alternative functional specifications, sampling issues, incorporating additional covariate sets, and alternative specifications of the first stage equation. We provide an extensive robustness analysis on the validity of our identification strategy, in particular on the exogeneity assumption.

We are not aware of any study analyzing the potential effect of taxing the carbon content of the entire energy tax base. This is of great importance as around $70 \%$ of global $\mathrm{CO}_{2}$ emissions comes from energy consumption. There are only 14 countries that have carbon taxation schemes. In eight of these countries, it only passed legislation after 2010, which explains the scarcity of empirical evidence on the effectivenes of carbon taxation. Having a detailed dataset on carbon content of energy consumption and exploiting the peculiar aspect of energy taxation, being a highly intertwined policy with carbon taxation, we are able to experiment the consequences of taxing the carbon content of energy use. There is recent literature investigating the effects of carbon taxation on various outcomes such as gasoline consumption or energy efficiency (Martin et al., 2014; Rivers and Schaufele, 2015; Lin and Li, 2011). Martin et al. (2014) analyse the effect of the Climate Change Levy (CCL) package including a carbon tax levied on the energy intensive manufacturing sectors in the United Kingdom. According to their findings, the introduction of the CCL in 2001 had a strong negative effect on energy intensity and electricity consumption in the subsequent years. This is in line with our findings. Although motivated by other concerns, their strategy of using a short time period for the pre- and post-impact duration is consistent with the potential endogeneity 
of taxation in the long-run.

Our paper contributes to the substantial body of literature estimating the price elasticity of energy resource consumption (see, among others, Nordhaus 1977; Schmalensee and Stoker 1999; Yatchew and No 2001; Li et al. 2014 ). In this literature, the tax rates are taken as exogenous, albeit the endogneity of prices to energy demand has recently been recognized (Davis and Kilian, 2011; Li et al., 2014; Coglianese et al., 2016). Our results indicate that this approach can lead to a bias due to endogeneity of taxes to energy demand.

Third, our results contribute to the empirical literature on strategic policy interaction. We document a positive correlation between the energy taxes of neighboring countries. First, the concern that this correlation might be driven by common time shocks is irrelevant to our setting, since we exploit cross-sectional variation. Second, we provide evidence that the energy tax base is likely to be immobile which rules out tax competition as an explanation. Therefore, the documented strategic policy interaction is likely to be in the form of yard-stick competition or due to expenditure spillovers such as pollution abatement. The main focus of the literature on startegic policy interaction is taxation of mobile bases such as capital income, gift, inheritance, alcohol, or cigarette taxation (Keen and Konrad, 2013; Devereux and Loretz, 2013). Empirical evidence for strategic policy interaction in energy resource taxation is scarce. Evers et al. (2004) provide evidence for diesel taxation for a sample of European countries. Devereux et al. (2007) show that gasoline excise taxes are positively correlated among the US states, but they also note that cross-border shopping of gasoline is costly, meaning that the correlation is likely to be driven by other factors than tax competition.

The rest of the paper is organized as follows. In Section 2, we describe our dataset and present some descriptive properties of our main variables. We explain our econometric model, estimation strategy, and identification strategy in Section 3. In Section 4, we present our estimation results. Section 5 introduces further analysis and robustness tests. Section 6 concludes and highlights some remarks. 


\section{Data and Descriptive Statistics}

Due to a lack of reliable dataset, performing a cross-country study on energy taxation has rather been difficult until recently. The best available and most comprehensive dataset has been the IEA/OECD dataset (IEA, 2016) on energy prices and taxes but this dataset suffers from several shortcomings. The database does not cover all fuels systematically while fuel taxes are observed for some countries but not for others. Moreover, countries often seem to apply taxes to specific fuel categories, but exempt or apply lower rates to large user categories from these tax bases at the same time. Such tax facilities or so called fossil fuel subsidies create large differences between nominal and effective tax rates (Ekins and Speck, 1999). Finally, there are several practical difficulties to link observed taxes and energy prices to the underlying energy consumption categories.

We employ the data on energy consumption and effective tax rates for 34 OECD countries from the current OECD report "Taxing energy use: A graphical analysis" (OECD, 2013b). ${ }^{5}$ It is based on the Taxing Energy Use (TEU) database which includes entire final consumption of energy and the net energy used in transmission and transformation. This total tax base is disaggregated into categories as a combination of major energy user categories and major fuel types. The major user categories are on-road transportation, off-road transportation, residential and commercial, industry, and electricity production. The major fuel categories are oil, coal and peat, natural gas, waste and combustibles, renewables, and nuclear. ${ }^{6}$

Energy consumption data in the TEU database is from the 2009 Extended World Energy Balances (EWEB) published by International Energy Agency (IEA, 2011). It is based on the Total Final Consumption (TFC) balance which is the domestic end-use of energy including imports. The TEU database also

\footnotetext{
${ }^{5}$ See Appendix A for the list of countries.

${ }^{6}$ The energy use and taxation data is also documented at a more detailed level. Specifically, there are 30 specific user categories and 65 fuel types. For the major tax base categories, effective tax rates are the average tax rate, weighted by the size of the tax base. Zero tax rates are included in the calculation.
} 
includes excise taxes levied directly on a physical unit. There are several groups of taxes excluded. First, taxes that apply not only to energy products but also to other goods, such as value-added and retail sales taxes, are not included in the TEU database, as they do not change relative prices. Second, the taxes that are not directly related to energy use, such as vehicle taxes and road user charges, are also excluded. Third, the TEU database also excludes production taxes, royalties, and taxes on the resource extraction activity, assuming that they do not have a substantial effect on domestic prices, since these taxes apply to internationally traded goods. ${ }^{7}$

Data on tax rates are those in effect as of April 1, 2012. The data is based on the information collected from the OECD/EEA database on instruments used for environmental policy (www.oecd.org/env/policies/database) and the European Commission (EC 2012), as well as from national sources such as legislation, government websites, or national officials. The database contains information on tax rates generally set per physical quantity of fuel, hence these tax rates are not directly comparable. These are converted to a common unit, Euro per gigajoule of energy or per tonne of $\mathrm{CO}_{2}$ emissions based on the standard IEA and IPCC conversion rates for specific fuels. Tax rates in national currency are converted to Euro based on the average exchange rates for the period from September 2011 to August 2012.

Importantly, the TEU database also provides detailed information on any tax rebates, credits, and other tax expenditures that apply to a specific tax base category, against the same disaggregation of users and fuels. Surrey (1985) defines some part of the tax concessions as hidden government spending, and develops the tax expenditure concept for the foregone tax revenues due to tax concessions. More specifically, governments report benchmark tax rates that would apply to a specific tax base if there were no tax concessions. The difference between the benchmark tax rate and the reduced tax

\footnotetext{
${ }^{7}$ The treatment of electricity is different from the TFC figures which includes the energy output. The TEU database includes only the energy used to generate electricity domestically rather than the output. Consistent with the treatment of taxes on other energy sources, taxes on the electricity consumption are the implicit rates on the underlying fuels used in electricity generation.
} 
rate due to tax concessions are reported as tax expenditures. The determination of benchmark tax rates varies across countries depending on the tax code. Therefore, neither the tax expenditures nor the benchmark tax rates are comparable across countries. The TEU database allows to calculate the effective tax rates as the net tax that apply after accounting for tax concessions. The effective tax rates reflect the true costs faced by the energy consuming segments of the society, and they are comparable across countries.

Energy taxation takes into account various considerations such as revenue requirement, creating competitive advantage for specific sectors, or addressing distributional concerns. These motivations might also be responsible for the cross-country variation in the tax expenditures. In the OECD countries, the support in the energy market are predominantly in the form of tax expenditures, rather than direct price subsidies (OECD, 2013a). Hence there is substantial difference between the nominal and effective energy tax $\operatorname{rates}^{8}$, and can result in misleading estimations, since the variation in the tax expenditures also driven by the subjective judgment of governments on the benchmark tax rates. In order to highlight its importance, in Appendix A, we show that these tax concessions are large in size and the cross-country variation is rather high.

Table 1: Descriptive statistics

\begin{tabular}{lccccccc}
\hline \hline & Units & \# Obs. & Mean & Median & St. Dev. & Min. & Max. \\
\hline Tax base & ths. ton. $\mathrm{CO}_{2}$ & 343 & 24576 & 5460 & 53166 & 0.548 & 429228 \\
Tax rate & Euro/ton. $\mathrm{CO}_{2}$ & 343 & 35.389 & 6.580 & 69.041 & 0.000 & 577.303 \\
\hline \hline
\end{tabular}

In our baseline analysis, we use the resource categories oil, natural gas, and coal and peat, since these are three major fossil fuels subject to a potential resource based carbon tax. For example, Metcalf (2009) argues that taxing carbon content of these fossil fuels is a cost effective and simple way of pricing carbon-dioxide emissions. Excluded resource categories represents a small fraction of the total emissions. More specifically, we exclude the renewable

\footnotetext{
${ }^{8}$ See Ekins and Speck (1999) for a detailed discussion
} 
and nuclear energy sources, since the size of the tax base is zero due to having zero emission. The waste and combustibles fuel category is also excluded. This category, as in the case of renewables, is subject to special tax treatment in the tax code in general, ie. mostly taxed at a zero effective rate once the tax reliefs are deducted. That is, these categories might introduce additional sources of heterogeneity due to government preferences, and they might not be the main target of a potential carbon tax. In addition, off-road transportation category is also excluded, mainly due to being a mobile sector, and hence being a threat to our identification strategy. Finally, a small number of outliers are also excluded due to having very high tax rates. Our sampling choices don't effect most of the results presented throughout the paper. We provide an analysis about the sensitivity of our baseline results to our sampling choices in Section 5. Using our baseline sample, Table 1 presents some descriptive statistics for the tax base and effective taxes together with their measurement units. Further descriptive analysis on the tax base size and the taxes are provided in Appendix A.

\section{Empirical Strategy}

This section presents our estimation strategy. Before describing our econometric model and identification strategies, we start with a discussion on the potential endogeneity of tax policies.

\subsection{Endogeneity of Energy Taxation}

In order to facilitate the discussion, here we start with the the commonly used ad-hoc specification for energy demand, leaving the detailed description of our econometric model to the next subsection. Consider the static specification for energy demand $(D)$ in region (country or federal states at the national level) $i$, at year $t$ :

$$
D_{i t}=\alpha_{i}+\gamma_{t}+\beta_{P} P_{i t}+X_{i t} \theta+\varepsilon_{i t},
$$


where $P_{i t}$ stands for the tax inclusive fuel prices, $X_{i t}$ is a row vector of observable control variables such as income and population, and $\theta$ is a column vector of parameters. Variables can be in levels or logarithms depending on the preferred specification. Here, $\alpha_{i}$ stands for region specific time invariant effects, $\gamma_{t}$ stands for common time effects across regions, and $\beta_{p}$ measures the responsiveness of energy consumption (eg. elasticity when the variables are in logarithms) with respect to energy prices.

Two concerns about this approach have been raised recently (Davis and Kilian, 2011; Li et al., 2014). Firstly, a simple OLS regression does not reflect a causal relation due to a clear endogeneity problem, at least in the form of simultaneity. Therefore, it is very likely that the identifying condition $E(P \varepsilon)=0$, indicating that prices and the error term are uncorrelated, does not hold. To deal with this problem, Davis and Kilian (2011) suggest to instrument tax exclusive prices with lagged taxes ${ }^{9}$, assuming that tax rates $\left(\tau_{i t}\right)$ are exogenous to the demand equation, that is $E(\tau \varepsilon)=0$. Therefore, they identify the causal effect of prices on consumption by exploiting the variation in prices, which is spanned by tax rates and which is assumed to be exogenous to consumption. The second concern is that response of energy consumption to the tax rates might be stronger than the repsonse to the prices, since tax changes are perceived as more persistent than price changes. Recently, Li et al. (2014) suggest a decomposition method to separately identify tax and price elasticities under the assumption that tax rates are exogenous. In this paper, we partial out price effects by using resource dummies, which can account for both of these problems. This point will be explained in more detail in the next subsection. Here we focus on the assumption of exogenous tax rates.

In this paper we argue that tax rates might be endogenous due to the fact that taxation is a decision variable as well as energy consumption. In particular, in the case of energy taxation, size of the tax base can be a strong motivation in the tax setting behavior. This is clearly visible when tax rates on different energy tax base categories are compared. In general, large tax-base

\footnotetext{
${ }^{9}$ Their estimations are in logarithms and in first differences due to employing monthly data.
} 
categories in terms of fuel or user categories are taxed at a higher rate. For example, gasoline, having a larger base compared to diesel, is generally taxed at a higher rate in most countries. Another example is that road transport is one of the most important revenue sources, and is taxed generally at a higher rate than other user categories. Tax reductions are generally applied to small tax bases in order to avoid erosion of the tax revenues. These type of concerns reflect the endogeneity of tax base categories which is a selection problem. This problem might have consequences also on tax base specific estimations (ie. household gasoline consumuption), if there is some heterogeneity in the government preferences across countries. In our setting, this potential source of bias can be easily accounted for by exploiting the structure of our dataset and using tax-base dummies.

Another source of potential endogeneity arises frequently when the variables of interest are decisions taken by different agents, which is clearly the case for energy consumption and taxation. More specifically a simultaneity problem is very likely when the decision maker chooses the explanatory variable by observing the dependent variable. Applied to our case, government preferences over energy taxes might be a function of the size and some unobserved characteristics of the energy tax base which, in turn, is a decision taken by the energy consumers as a function of tax rates. An example might be environmental concerns. Governments might explicitly adjust their policies as the size of the tax base increases. Another example is that, if there is a revenue target determining the taxation levels, even an exogenous negative shock to the size of the tax base may lead the government to adjust the taxes accordingly.

This is clearly a long-run concern; however, it has implications also for short-run panel estimations employing the specification in equation (1). Specifically, avoiding this potential problem requires a dynamic specification where lagged consumption is included as a covariate to control for feedback effects. This specification is not new in this specific context; however, the main motivation has been to control for the exogenous factors leading to a persistence over time in the energy consumption patterns. Our results indicate that a dynamic 
specification is necessary, not just for efficiency, but also for unbiasedness.

\subsection{Econometric Specification}

Our estimations employ the common ad-hoc specification for the energy consumption $(D)$ by sector $s$, produced from resource type $r$, in country $i$ :

$$
D_{i r s}=\alpha(i, r, s)+\beta_{\tau} \tau_{i r s}+X_{i r s} \gamma+\varepsilon_{i r s}
$$

where $\beta_{\tau}$ measures the effect of taxes, $\tau_{i r s}$, and $\gamma$ is the coefficient vector of a set of controls, $X_{i r s}$. The variables are in levels or logarithms depending on the ad-hoc specification. The term $\alpha(i, r, s)$ plays a crucial role in our identification strategy and denotes the set of effects that we can control for by introducing country, sector and resource category dummies, and even their interactions.

Importantly, we can partial out the variation due to most of the potential elements in $X_{\text {irs }}$ with our control set $\alpha(i, r, s)$. In the following, we explicitly state this control set and discuss each element extensively:

$$
\alpha(i, r, s)=\left\{\alpha_{i}, \alpha_{r}, \alpha_{s}, \alpha_{i r}, \alpha_{i s}, \alpha_{r s}\right\}
$$

Here, $\alpha_{i}$ are country dummies controlling for specific effects which are invariant across use and resource categories. Such effects are generally introduced explicitly in country level estimations such as income level (generally measured b GDP), population (or income per capita if population is not explicitly controlled for), or some measures of sectoral composition. They can also control for the country level tax-exclusive energy price effects. By taking advantage of our dataset we can control for both observable and potential unobservable country level effects in a cross-sectional framework, providing estimates for the long-run responsiveness of energy demand to taxes.

Secondly, $\alpha_{r}$ stands for resource specific effects, which are invariant across countries and user categories. Most importantly, these dummies partial out the effects of relative resource prices. Not only the own price effects but 
also the cross-price effects can be accounted for by these controls. Therefore, our estimations also account for substitution effects resulting from changes in relative resource prices. By employing $\alpha_{r}$ in our control set, we account for the variation in the average relative prices of various energy resources at the global level. This might be sufficient for some resources, for instance for oil which has been argued to be subject to a global market. On the other hand, markets for coal and natural gas are more regionalized. We can further control for this variation in prices across countries by interacting resource and country dummies denoted with the set of dummies $\alpha_{i r}$. Here, another reasonable strategy is to interact the resource dummies with region dummies instead of country dummies which alleviates the degrees of freedom problem.

Third, user category dummies, $\alpha_{s}$, can control for sectoral differences leading to a variation in the energy consumption levels, and which are systematic across countries and resource types. These differences might vary over countries and resource types depending on the energy intensities or value added in GDP. These effects can be accounted for by the interaction terms, $\alpha_{i s}$ and $\alpha_{r s}$ respectively.

In this specification, the interaction term $\alpha_{r s}$, namely the tax base dummies, plays a crucial role. Specifically, this control set can account for the selection bias due to the endogeneity of tax base categories to a large extent. We will show that this selection bias is strong and leads to a spurious positive correlation between the tax base size and tax rates.

In our baseline specification we control for only the main effects $\alpha_{i}, \alpha_{r}, \alpha_{s}$ and the tax base dummies $\alpha_{r s}$, since the other interaction effects, $\alpha_{i s}$ and $\alpha_{i r}$, introduces an enormous number of parameters to be estimated leading to a degrees of freedom problem. We will show that the additional variation explained by these interaction effects is not much. Still, it is important to account for a potential omitted variables bias due to excluding these interactions. Therefore, we conduct IV estimations as explained in the next subsection. 


\subsection{Identification Strategy: Strategic Policy Interaction}

Our control set explains much of the variation in the energy consumption patterns. This leaves a very specific variation to identify the hypothesized effect and provides a reliable conditioning set for our instrumental variables estimations. Still there are further reasons to be skeptical about an endogeneity in the remaining variation. First, it is not possible to include all the interaction terms with the country dummies as explained in the previous subsection. Second, there is a potential simultaneity problem due to the joint determination of energy consumption and tax rates (at least in the long-run) which can lead to a variation also at the intersection of the three dimensions in our dataset, namely country, sector, and resource type.

In identifying the long-run causal effect of energy taxes on energy demand, we base our identification strategy on the strategic policy interaction literature which hypothesize a significant correlation among policies across countries. The common empirical approach is to estimate a reaction function in the form of

$$
\tau_{i}=\beta_{0}+\beta_{1} \tau_{-i}+X_{i} \gamma+\nu_{i}
$$

where $\tau_{i}$ is the own tax rate, $X_{i}$ is a matrix of a control set with the associated coefficient vector of $\gamma$, and $\nu_{i}$ is the error term. The crucial element is $\tau_{-i}$ which is formulized as the weighted average of other countries' tax rates

$$
\tau_{-i}=\sum_{j \neq i} \omega_{i j} \tau_{j} .
$$

The choice of weights, $\omega_{i j}$ such that $\sum_{j \neq i} \omega_{i j}=1$, relies on priors about the exogenous factors, such as geographic or demographic characteristics, which might have a role in the intensity of the hypothesized interaction. In our estimations, we use various weighting schemes which are commonly employed in the literature. In this setting, rejecting the null hypothesis of $\beta_{1}=0$ is considered as evidence for strategic interaction. There is an extensive theoretical literature explaining this correlation with different mechanisms which 
is important for the validity of our estimations aiming to identify a causal relationship.

Equation (3) is the base for our identification strategy. In particular, we use the tax levels of neighboring states as instruments for the own tax rates. The first condition for being a valid instrument is relevance which requires a sufficient correlation between the endogenous regressors and the instruments. In the following sections, we document a positive correlation for the case of energy taxes which is consistent with the various theoretical models in the literature on strategic policy interaction. The source of the correlation is not important for the consistency of an IV estimation, since the first stage regression does not have to reflect a structural relationship. However, it is crucial to discuss the implications of possible explanations for the exogeneity of our instrument. More specifically, a valid instrument, $Z$, should also satisfy exogeneity, $E[Z \varepsilon]=0$, meaning that instruments should not be correlated with the error term of the second-stage regression. In our case, this condition requires that energy taxes should not be related to energy demand of the neighboring states via any other channel than the correlation between the tax levels of neighboring states. More explicitly, the required condition is

$$
E\left[\left(\sum_{j \neq i} \omega_{i j} \tau_{j}\right) \varepsilon_{i}\right]=0
$$

This condition boils down to the degree of mobility of the tax base which is one of the main underlying features in classifying the models of strategic policy interaction as in Brueckner (2003) and Revelli (2005).

Brueckner (2003) explicitely frames models of strategic interaction into two broad categories that fits perfectly into our discussion. These are spillover models and resource-flow models. The main distinction between these two groups of theories is that the resource-flow models rely on the mobility of the tax base, while spill-over models do not. Proposed mechanisms for tax mimicking which rely on pollution, expenditure, and informational spillovers are categorized as spill-over models. For example, according to the yardstick competition literature, following Besley and Case (1995), it is entirely the political 
process and informational spill-overs that leads to tax mimicking. Political parties, competing in elections, are forced to adjust their policy accordingly, when the voters evaluate the policies relative to those of the neighboring states. This explanation implies that the taxation level in one state affects the neighbor's tax levels, but not the tax base directly. This is exactly the requirement for the neighboring tax rates to satisfy the exogeneity condition. This is also the case for expenditure spill-over models where public goods provision in one state affects the well-being in the other state, as in Case et al. (1993), or in pollution spill-over models with trans-boundary pollution as in Murdoch et al. (1997) or Fredriksson and Millimet (2002).

The other explanation for a potential positive correlation among tax rates of neighboring states is tax competition which suggests a "race to the bottom" and fits into the resource-flow models. ${ }^{10} \mathrm{It}$ is argued that countries compete over mobile tax bases which leads to tax mimicking. That is, by setting lower tax rates countries can attract mobile tax bases, which in turn leads the neighboring states to lower their corresponding tax rates. This implies a causality chain running from tax rates to neighboring tax base. Tax competition is predominantly studied for taxation of capital income, inheritance and gifts, or high income earners for which the tax bases are potentially highly mobile. Although there is a significant literature investigating tax competition in the commodity or the factor input markets, it is relatively small, potentially due to lesser mobility of the tax bases. Subjects to this literature are alcohol and cigarettes for which cross-boder shopping or smuggling are not very costly.

The energy tax base is arguably sufficiently immobile, and our identification strategy relies on this assumption. We provide an extensive analysis on this exogeneity assumption where the results indicate that tax competition is not likely in our setting. In our sample, one troublesome category which might threaten our identification strategy is on-road oil consumption. There are some studies investigating strategic interaction in gasoline and diesel consumption

\footnotetext{
${ }^{10}$ See Keen and Konrad (2013) for an extensive survey of the theoretical literature, and Devereux and Loretz (2013) for the recent advances in the empirical literature on tax competition.
} 
(Evers et al., 2004; Devereux et al., 2007). However, as argued by Devereux et al. (2007), cross-border shopping of oil products is likely to be uneconomic, and even if there exists some, this is potentially a side-effect of cross-border shopping for other items such as cigarettes and alcohol. Overall, the size of such an effect is unlikely to be significant for the whole energy tax base to threaten the exogeneity of neighboring states' tax rates on own energy consumption.

Another potential threat might be pollution havens. That is, by applying relatively less stringent environmental regulations, less developed regions might attract more investment. This type of strategic interaction is generally hypothesized to exist among the developing and the developed countries. It is not very likely that this relocation of large multinational firms, if exists at all, has a systematic pattern across neighboring countries, in particular in our sample of OECD countries. This is consistent with the findings in Martin et al. (2014) that the introduction of the CCL in UK had no effect on employment, revenues, and plant exists.

We conclude this section with some final remarks. First, condition 4 requires the weighting matrix should also be orthogonal to the second stage errors. Therefore, the choice of the weighting matrix is important. For example, our baseline weighting matrix depends on the distance to one neighbor relative to another neighbor, since the weighting matrix is constructed such that $\sum_{j \neq i} \omega_{i j}=1$. We do not see any particular reason for this to be a threat to our identifying condition. Second, the parameter estimates in the first stage equation should be interpreted with caution, since there is an endogeneity problem by construction. Intuitively, the neighbor's tax, $\tau_{-i}$ is correlated with $\nu_{i}$ as long as $\beta_{1}$ is not equal to zero. So, the estimated first stage parameter of the instrument is biased. However, 2SLS estimation does not impose any identification restriction for the first stage equation. Hence, this situation does not have any implications on the identification of tax responsiveness of energy demand. ${ }^{11}$

\footnotetext{
${ }^{11}$ See Wooldridge (2010) for a detailed explanation.
} 


\section{Baseline Results}

This section presents our baseline results. The results from the OLS estimations, where we regress logarithm of energy consumption on effective taxes by introducing various elements of our control set are presented in the first four columns of Table (2). All regressions control for the main effects via the inclusion of country, use, and resource dummies in the control set. Regression (1) includes the main effects only. The estimated coefficient of energy tax is positive and significant. This is at odds with the basic intuition that higher tax levels should reduce the energy demand. Therefore, the OLS estimates are likely to be biased. In the following columns, we introduce our additional control sets. Regression (2) additionally controls for tax base specific effects via including the use-resource interaction dummies. This increases the explanatory power of the model substantially. The adjusted $R^{2}$ is 0.77 , while it was 0.44 in regression (1). Furthermore the estimated effect falls into the reasonable range. It is negative and significant. This result reflects our concern about the selection bias due to the endogeneity of tax base categories which can be ruled out by using use-resource interaction dummies. For instance, the resource-use category of "Oil - Transport" generally has a larger tax base than both other fuels used in transportation and other energy use categories consuming oil products and is also subject to higher tax rates. ${ }^{12}$ Such effects can lead to the presented spurious positive correlation in regression (1). Another possibility is that some country invariant characteristics, specific to each tax base, which is defined over the resource and sector combinations, play a substantial role in explaining the variation in the energy demand. The resource-use interaction dummies can also control for such systematic variation.

Our dataset allows for a rich set of controls. In the other columns, we further control for country-resource and country-sector specific interaction effects. The country-resource interaction dummies are included in the control set in regression (3). The estimated effect is not significantly different from that of regression (2) and the adjusted $\mathrm{R}^{2}$ remains almost the same. That is, using

\footnotetext{
${ }^{12}$ See Figures (2) and (3) in Appendix A.
} 
Table 2: Baseline Regressions

\begin{tabular}{|c|c|c|c|c|c|}
\hline \multicolumn{6}{|c|}{ Dependent Variable: $\log$ (Size of Tax Base in $\mathrm{CO}_{2}$ Emissions) } \\
\hline & OLS & Baseline OLS & OLS & OLS & Baseline IV \\
\hline & $(1)$ & $(2)$ & $(3)$ & $(4)$ & $(5)$ \\
\hline \multirow[t]{2}{*}{ Tax } & $0.013^{*}$ & $-0.003^{* * *}$ & $-0.003^{* * *}$ & -0.001 & $-0.007^{* * *}$ \\
\hline & $(0.010)$ & $(0.001)$ & $(0.001)$ & $(0.003)$ & $(0.001)$ \\
\hline Main effects & Yes & Yes & Yes & Yes & Yes \\
\hline Use-Res. effects & No & Yes & Yes & Yes & Yes \\
\hline Cnt.-Res. effects & No & No & Yes & No & No \\
\hline Cnt.-Use effects & No & No & No & Yes & No \\
\hline Adjusted $R^{2}$ & 0.439 & 0.771 & 0.796 & 0.774 & 0.746 \\
\hline Observations & 343 & 343 & 343 & 343 & 268 \\
\hline
\end{tabular}

Notes: Robust standard errors clustered two-way by country and tax base (use-resource) dimensions are in parentheses. Significance of the coefficients is labeled as ${ }^{*} p<0.10,{ }^{* *}$ $p<0.05,{ }^{* * *} p<0.01$.

this extra control set does not provide a further advantage by improving the explanatory power of the model, while introducing extra complexity. Regression (4) controls for country-sector specific effects instead of country-resource specific effects. This strategy deteriorates the precision of the estimated tax effect and even reduces the adjusted $R^{2}$. This is not an anomalous result in the sense that country-resource and in particular country-sector interaction dummies introduce a large number of parameters to be estimated and reduces the degree of freedom substantially. In the next section, we deal with this problem by using region dummies which is an intuitive strategy given the regional aspect of energy resource markets.

Given the above results, we conduct our baseline IV estimations by employing the specification in regression (2). Since the results from the first stage IV regressions are interesting and deserve further attention, here we only present the second stage result and provide an extensive analysis of the first stage results in the next section by incorporating different weighting schemes. Our baseline IV estimation is presented in the last column of Table (2), where we 
use squared-distance as the weighting matrix in the corresponding first stage estimation. The estimated size of the tax effect is almost three times higher than the one in the baseline OLS estimation and is highly significant. This result confirms our intuition that tax rates are endogenous. Furthermore, given the explanatory power of our control set, this is likely to be a simultaneity problem, rather than an omitted variables problem. We analyze the validity of our identification strategy in the following sections.

The coefficient estimates in Table (2) are the predicted average proportional changes in energy consumption due to a 1 Euro increase in the energy taxes which is levied per tonnes of $\mathrm{CO}_{2}$ emissions from energy consumption. Our baseline IV estimation indicates that a 1 Euro increase in the energy taxes will reduce $\mathrm{CO}_{2}$ emissions from energy consumption by 0.73 percent in the long-run. When calculated at the mean value of energy taxes (weighted by the base size), the estimated coefficient implies an elasticity of 0.28 , which is substantial. This result suggests that energy taxation can be an effective tool for countries to achieve their goal to reduce $\mathrm{CO}_{2}$ emissions.

\section{$5 \quad$ Further Analysis and Robustness Tests}

In this section we provide further analysis and present various robustness tests on the baseline results. In Section (5.1) we present the results on the strategic policy interaction in the energy sector and the corresponding second stage IV estimations. Section (5.2) includes an analysis on the validity of this identification strategy following Revelli (2005). In Section (5.3) we use some political correlates of energy taxes as additional instruments to perform exogeneity tests. Section (5.4) explores sensitivity of our results to the functional specification of our econometric model. We introduce an extra control set in Section (5.5), namely region dummies. We analyze robustness of the baseline results to various sampling issues in Section (5.6). 


\subsection{Strategic Policy Interaction and IV Estimations}

Table (3) presents the strategic policy interaction estimations which form the first stage of our IV estimations. The regressions employ the baseline control set which includes country and tax base dummies, and each regression refers to a different weighting scheme. In all specifications, we assign zero weight to non-contiguous countries, hence island countries drop out of the sample. Regression (1) employs a uniform weighting scheme assigning equal weights to each neighboring country which is generally taken as the baseline in empirical tests of the strategic policy interaction. The correlation is positive and significant confirming policy mimicking among neighboring countries. In order to construct the weighting matrices in the subsequent columns, we employ distance, distance squared, area, and population density. Regression (3) corresponds to our baseline IV estimation presented in Table (2). These nonuniform weighting matrices lead to similar results in size, sign, and significance of the hypothesized relationship. There are two noteworthy points: First, the estimated size of the effect from these non-uniform weighting schemes is almost twice as large as the one from the uniform weighting, and second, non-uniform weighting increases the precision substantially. These results illustrate the importance of using exogenous non-uniform weighting schemes in estimating strategic policy interactions.

Table 3: Strategic Policy Interaction

\begin{tabular}{lccccc}
\hline \hline \multicolumn{2}{l}{ Dependent Variable: Own Tax } & & & \\
\hline Weighting & Uniform & $1 /$ Distance & $1 /$ (Distance sq.) & $1 /($ Area $)$ & Pop. Dens. \\
& $(1)$ & $(2)$ & $(3)$ & $(4)$ & $(5)$ \\
\hline Neighbours' Tax & $0.124^{*}$ & $0.266^{* * *}$ & $0.265^{* * *}$ & $0.236^{* * *}$ & $0.240^{* * *}$ \\
& $(0.069)$ & $(0.057)$ & $(0.076)$ & $(0.083)$ & $(0.072)$ \\
\hline Adjusted $R^{2}$ & 0.559 & 0.567 & 0.563 & 0.561 & 0.563 \\
Observations & 268 & 268 & 268 & 268 & 268 \\
\hline \hline
\end{tabular}

Notes: Robust standard errors clustered two-way by country and tax base (use-resource) dimensions are in parentheses. Significance of the coefficients is labeled as ${ }^{*} p<0.10,{ }^{* *}$ $p<0.05,{ }^{* * *} p<0.01$. 
We use this strong and robust correlation to identify the effectiveness of a carbon tax levied on per unit of emissions from energy consumption. We apply two stage least squares (2SLS) estimations for which the presented regressions in Table (3) form the first stages. The corresponding second stage regressions are presented in Table (4). The baseline IV estimation (see Table (2)) is presented in Column (3) together with the associated first stage statistics to evaluate its validity as an instrument. In the first column, the estimated effect is marginally insignificant at the $10 \%$ significance level. This might be due to the weakness of the correlation between the instrument and the endogenous regressor in the first stage when uniform weighting is used. In contrast, using non-uniform weightings in the first stage leads to quite robust results in size and significance, as can be seen in columns (2) to (5).

Table 4: Instrumental Variables Estimations

Dependent Variable: $\log$ (Size of Tax Base in $\mathrm{CO}_{2}$ Emissions)

\begin{tabular}{|c|c|c|c|c|c|}
\hline Weighting of Instrument & $\begin{array}{l}\text { Uniform } \\
\text { (1) }\end{array}$ & $\begin{array}{c}\text { 1/Dist. } \\
(2)\end{array}$ & $\begin{array}{c}1 /(\text { Dist. sq. }) \\
(3)\end{array}$ & $\begin{array}{c}1 /(\text { Area }) \\
(4)\end{array}$ & $\begin{array}{c}\text { Pop. Dens. } \\
\text { (5) }\end{array}$ \\
\hline Tax & $\begin{array}{l}-0.004 \\
(0.003) \\
\end{array}$ & $\begin{array}{c}-0.007^{* * *} \\
(0.002) \\
\end{array}$ & $\begin{array}{c}-0.007^{* * *} \\
(0.001) \\
\end{array}$ & $\begin{array}{c}-0.006^{* * *} \\
(0.002) \\
\end{array}$ & $\begin{array}{c}-0.006^{* * *} \\
(0.002) \\
\end{array}$ \\
\hline Adjusted $R^{2}$ & 0.753 & 0.748 & 0.746 & 0.750 & 0.750 \\
\hline Observations & 268 & 268 & 268 & 268 & 268 \\
\hline \multicolumn{6}{|l|}{ First stage statistics } \\
\hline Cragg-Donal Wald F stat. & 7.802 & 10.150 & 12.387 & 10.329 & 8.995 \\
\hline Kleibergen-Paap rk. F stat. & 2.511 & $8.706^{++}$ & $17.308^{+++}$ & $9.522^{++}$ & $6.416^{+}$ \\
\hline
\end{tabular}

Notes: Robust standard errors clustered two-way by country and tax base (use-resource) dimensions are in parentheses. Significance of the coefficients is labeled as ${ }^{*} p<0.10$, ${ }^{* *} p<0.05,{ }^{* * *} p<0.01$. Rejection of maximal size bias, under $5 \%$ true rejection rate, indicated as ${ }^{+++} 10 \%,{ }^{++} 15 \%,{ }^{+} 20 \%$.

Importantly, in our baseline IV estimation (Column (3)), weak identification is rejected by conventional tests. Under identically and independently distributed (iid) errors assumption, the Wald F statistic is 12, which satisfies the the rule of thumb of being higher than 10 to reject weak identification. Being a consistent test with the non-iid errors assumption in all our regressions, 
the Kleibergen-Paap rk F-statistic is 17, rejecting a maximal size bias of more than $10 \%$. As can be seen in Table (4), this result is generally robust across alternative non-uniform specifications of the weighting matrix, whereas the confidence levels are lower compared to our baseline estimation, and uniform weighting leads to a clear weak instrumentation.

\subsection{Testing Tax Competition}

There is an inherent endogeneity in the first stage regressions presented in Table (3). The reason is that, by construction, the error terms are correlated with the dependent variable (see, among others, Brueckner (2003) and Devereux and Loretz (2013) for a more detailed discussion). Therefore a structural interpretation should be avoided. Furthermore, since all the strategic policy interaction models imply the same reaction function, our estimations are evidence only towards a policy convergence, yet they do not reveal the exact mechanism leading to this correlation. However, as discussed in Section 3.3, for the purpose of using this strong correlation as an identification strategy, one does not need to identify the underlying factors, since the first stage regression is just a linear projection of the instrument on the endogenous variable in a 2SLS framework (see the discussion in Section 3.3).

The crucial requirement, upon the relevance condition, is that the instrument should not be correlated with the second stage errors. That is, the tax rates should not have a direct effect on the tax base of neighboring countries other than its indirect effect through neighbors' tax rates. It is not possible to test this requirement directly in our just-identified model. However, as discussed in the previous sections, our extensive control set is able to account for the conventional control variables for energy consumption. In the following sections, we will extend this control set further by using region dummies. Conditioning our identification strategy on our control set provides an extra confidence to the exogeneity of our instrument. A remaining concern is related to the potential direct relations between energy taxes and the neighboring countries' tax base. For this reason, the structural meaning of the first 
stage regressions is important.

Table 5: Testing Tax Competition

\begin{tabular}{lccccc}
\hline \hline \multicolumn{6}{l}{ Dependent Variable: $\log$ (Size of Tax Base in CO2 Emissions) } \\
\hline Weights & Uniform & $1 /$ Distance & $1 /$ (Distance sq.) & $1 /($ Area $)$ & Pop. Dens. \\
\hline Own Tax & $(1)$ & $(2)$ & $(3)$ & $(4)$ & $(5)$ \\
\hline \multirow{2}{*}{ Neighbours' Tax } & $-0.003^{* * *}$ & $-0.003^{* * *}$ & $-0.003^{* * *}$ & $-0.003^{* * *}$ & $-0.003^{* * *}$ \\
& $(0.001)$ & $(0.001)$ & $(0.001)$ & $(0.001)$ & $(0.001)$ \\
& -0.000 & -0.001 & -0.001 & -0.001 & -0.001 \\
Adjusted $R^{2}$ & $0.001)$ & $(0.001)$ & $(0.001)$ & $(0.001)$ & $(0.001)$ \\
Observations & 0.753 & 0.753 & 0.753 & 0.753 & 0.753 \\
\hline \hline
\end{tabular}

Notes: Robust standard errors clustered two-way by country and tax base (use-resource) dimensions are in parentheses. Significance of the coefficients is labeled as ${ }^{*} p<0.10,{ }^{* *}$ $p<0.05,{ }^{* * *} p<0.01$.

More specifically, our identification strategy is not valid if the observed correlation between the tax rates of neighboring countries is due to tax competition where the mobility of the tax base with respect to the neighbor's tax policy is the underlying factor (see the discussion in Section (3.3)). In order to test this possibility, we follow Revelli (2005) and estimate the equilibrium relationship implied by the tax competition models. This is simply done by regressing the size of the tax base on both the tax rate and the weighted average of neighbors' tax rates as follows:

$$
D_{i r s}=\alpha(i, r, s)+\beta_{0} \tau_{i r s}+\beta_{1} \tau_{-i, r s}+X_{i r s} \gamma+\varepsilon_{i r s} .
$$

Here, if the null hypothesis of $\beta_{1}=0$ is not rejected, this is considered as suggestive evidence against tax competition. However, it should be noted that this is neither a test of exogeneity of the instrument nor an exact test of alternative explanations. The underlying structural assumption excludes the possibility of other types of strategic interactions. Furthermore, the results might also be driven by multicollinearity due to the strong correlation between $\tau_{i r s}$ and $\tau_{-i, r s}$. The results are presented in Table (5). The estimates are robust 
across all specifications. The estimation results for the own tax are similar to the baseline OLS result. The neighbors' taxes are insignificant, and its estimated size is small. As a result, there is no evidence for a tax competition under the mentioned assumptions.

\subsection{Political Correlates of Taxation as Additional Instru- ments}

Testing the exogeneity assumption in a more general manner requires extra instruments. However, finding a truly exogenous variation in the endogenous variables is a difficult task. In general, using invalid instruments increase the IV-bias substantially. Therefore, stability of the results to using additional instruments, which are arguably exogenous conditional on some observables, can be exploited to test exogeneity. In this section, we use some political correlates of taxation which are plausibly exogenous conditional on income and population. These are ethnic fractionalization, having a proportional electoral regime, having a presidential regime, and being a former British colony. ${ }^{13}$

Both the first and second stage results are presented in Table 6 where all regressions control for GDP and population. A potential drawback of this approach is that we have to replace the country dummies with a set of observable country level controls such as GDP and population. In the first regression, we replicate our baseline IV estimation without any extra instrument in order to address this concern. The results are very similar. Therefore, conditioning the exogeneity of neighbor's tax on the country dummies might be a much stronger assumption than what would be necessary.

In each of the following columns, we use an additional instrument. We start with evaluating the second stage results. In the upper panel of Table 6 , it can be seen that our baseline results on the effectiveness of carbon taxation is generally robust, in particular when the dummies for proportional and presidential regimes are incorporated as additional instruments. Use of

\footnotetext{
${ }^{13}$ The data for political variables come from the Database of Political Institutions by the World Bank (Beck et al., 2001). The data for GDP and population are from the World Development Indicators Database by the World Bank.
} 
Table 6: Political Correlates as Additional Instruments

\begin{tabular}{|c|c|c|c|c|c|}
\hline \multicolumn{6}{|c|}{ Dependent Variable: $\log$ (Size of Tax Base in $\mathrm{CO}_{2}$ Emissions $)$} \\
\hline Extra Instrument & $\begin{array}{l}- \\
(1)\end{array}$ & $\begin{array}{c}\text { Eth. Frac. } \\
\text { (2) }\end{array}$ & $\begin{array}{c}\text { Propor. } \\
(3)\end{array}$ & $\begin{array}{l}\text { Presid. } \\
\text { (4) }\end{array}$ & $\begin{array}{c}\text { Brit. col. } \\
\text { (5) }\end{array}$ \\
\hline $\operatorname{Tax}$ & $\begin{array}{c}-0.007^{* * *} \\
(0.002)\end{array}$ & $\begin{array}{l}-0.005^{*} \\
(0.003)\end{array}$ & $\begin{array}{c}-0.007^{* * *} \\
(0.002)\end{array}$ & $\begin{array}{c}-0.006^{* * *} \\
(0.002)\end{array}$ & $\begin{array}{c}-0.010^{* * *} \\
(0.002)\end{array}$ \\
\hline Adjusted $R^{2}$ & 0.75 & 0.76 & 0.75 & 0.75 & 0.74 \\
\hline Observations & 268 & 268 & 268 & 268 & 268 \\
\hline \multicolumn{6}{|c|}{ First Stage: Dependent variable is own tax } \\
\hline Neighbours' Tax & $\begin{array}{c}0.369^{* * *} \\
(0.072)\end{array}$ & $\begin{array}{c}0.312^{* * *} \\
(0.054)\end{array}$ & $\begin{array}{c}0.355^{* * *} \\
(0.066)\end{array}$ & $\begin{array}{c}0.366^{* * *} \\
(0.071)\end{array}$ & $\begin{array}{c}0.369^{* * *} \\
(0.076)\end{array}$ \\
\hline Political Correlate & & $\begin{array}{c}-64.528^{* * *} \\
(22.141)\end{array}$ & $\begin{array}{c}31.522^{* * *} \\
(8.999)\end{array}$ & $\begin{array}{c}-9.600 \\
(12.839)\end{array}$ & $\begin{array}{c}-28.587^{* * *} \\
(9.519)\end{array}$ \\
\hline Hansen J stat. (p-val) & & 0.385 & 0.499 & 0.178 & 0.129 \\
\hline Cragg-Donald Wald F stat. & 27.313 & 21.988 & 18.081 & 13.967 & 18.288 \\
\hline Kleibergen-Paap rk. F stat. & $26.165+++$ & $21.914+++$ & $16.435++$ & $14.397++$ & $12.776++$ \\
\hline
\end{tabular}

Notes: Robust standard errors clustered two-way by country and tax base (use-resource) dimensions are in parentheses. Significance of the coefficients is labeled as ${ }^{*} p<0.10$, ${ }^{* *} p<0.05,{ }^{* * *} p<0.01$. Rejection of maximal size bias, under $5 \%$ true rejection rate, indicated as ${ }^{+++} 10 \%,++15 \%,+20 \%$. 
ethnic fractionalization and being a former British colony leads to slightly different point estimates compared to the baseline result, but this difference is not statistically significant. Most importantly, in all regressions, based on the overidentification tests (see Hansen J statistics), the null hypothesis of exogeneity cannot be rejected. The degree of the stability in the coefficient estimates across specifications supports this conclusion. This can also be considered as an alternative test to distinguish between the resource-flow and the spillover models.

The first stage results are presented in the lower panel of Table 6 . The estimated effect of neighbor's tax is robust across all specifications. In the second column, the estimated coefficient for ethnic fractionalization is negative and highly significant. According to Alesina and Spolaore (1997), the higher fractionalization is, the higher the distance between the preference of the median voter for a public good provision and any point in the preference distribution of the society. The reason is the underlying assumption that the utility from the public good decreases with an increasing number of type of preferences which parametrizes the fractionalization in the society. This might lead to a lower government size. This suggest lower taxation in highly fractionalized societies, which is in line with the results in column (2).

Next, we use having a proportional electoral system dummy as a covariate. According to a Downsian model of party competition in Milesi-Ferretti et al. (2002), majoritarian electoral regimes are associated with less public goods, since majoritarian elections increase party competition. The estimated coefficient of having a proportional electoral system is positive, which is in line with this intuition.

Persson et al. (2000) argue that a presidential regime is associated with less legislative cohesion and more separation of powers. Due to these differences, it is argued that the size of the government in presidential regimes can be lower. As a result, this suggests a negative effect of having a presidential regime on energy taxes. A similar reasoning can be proposed for colonial origins. It is argued that checks and balances in the political process is a crucial determinant of economic performance, and countries with British colonial origin posses a 
higher degree of these (Acemoglu and Robinson, 2001). As in the case of having a presidential regime, where the degree of checks and balances is higher, the government size can be lower when the country is a former British colony. The sign of the estimated coefficients in columns (4) and (5) are consistent with this line of reasoning. However, the presidential dummy is insignificant.

\subsection{Functional Specification}

In our baseline model, we employ a log-linear specification which is common in empirical policy evaluation studies due to its advantage of a straight forward evaluation of the estimated size of the tax effect. We have three further motivations. First, the effective taxes are characterized by many zeros and taking logarithm leads to a substantial loss of observations. Although there is no restriction on the distribution of independent variables in an OLS framework, when a covariate, $X$, includes many zeros, the common strategy of applying a $\log (1+X)$ transformation is misleading, since the estimations will be quite sensitive to the unit of measurement. The second and more important reason is related to the first stage specification of our IV estimations. In the empirical tax competition literature, the estimated reaction functions are generally linear in the levels. Although consistency of an IV estimation does not require a correctly specified first stage equation, misspecification can lead to a weak instrumentation problem. A final reason to employ a log-linear model is that it is consistent with the strategy of eliminating resource price effects via the resource dummies.

In this section, we perform robustness tests on the functional specification of our econometric model. One reason to employ a log-linear form as our baseline is to avoid a weak correlation in the first stage. This point is illustrated in Column (1) and (2) of Table (7) where we conduct our baseline OLS and IV estimations by employing a log-log specification. The number of observations reduces substantially in each case, since the zero tax rates are dropped due to the logarithmic transformation. The estimated elasticities are close to their baseline counterparts. The estimated elasticity from OLS regression is 1.2 
and marginally insignificant at the $10 \%$ significance level. The IV estimation indicates an elasticity of 0.28 , but is highly insignificant. In contrast to the previous findings, the Kleibergen-Paap test implies a clear weak identification problem in the IV estimation which might be the underlying reason in the high imprecision of the IV estimation.

Table 7: Functional Specification

\begin{tabular}{lcccc}
\hline \hline \multicolumn{2}{l}{ Dependent Variable: Size of Tax Base in CO2 Emissions } \\
\hline \multicolumn{4}{c}{$\log -$ log } & \multicolumn{2}{c}{ linear in levels } \\
\hline & $(1)-$ OLS & $(2)-$ IV & $(3)-$ OLS & $(4)-$ IV \\
\hline Tax & -0.120 & -0.285 & -36322 & $-304975^{* * *}$ \\
& $(0.082)$ & $(0.378)$ & $(30603)$ & $(100404)$ \\
\hline Adjusted $R^{2}$ & 0.749 & 0.717 & 0.517 & 0.458 \\
Observations & 269 & 210 & 343 & 268 \\
\hline First stage statistics & & & & $0.266^{* * *}$ \\
Neighbours' Tax & & 0.197 & $(0.064)$ \\
& & $(0.128)$ & & 12.387 \\
Cragg-Donald Wald F stat. & & 4.577 & & $17.308^{+++}$ \\
Kleibergen-Paap rk. Fstat. & & 2.342 & & \\
\hline \hline
\end{tabular}

Notes: Robust standard errors clustered two-way by country and tax base (use-resource) dimensions are in parentheses. Significance of the coefficients is labeled as ${ }^{*} p<0.10$, ${ }^{* *} p<0.05,{ }^{* * *} p<0.01$. Rejection of maximal size bias, under $5 \%$ true rejection rate, indicated as ${ }^{+++} 10 \%,++15 \%,+20 \%$.

The results from employing a linear functional form are presented in Columns (3) and (4). Interestingly, the implied elasticities are also in line with their baseline counterparts. The implied elasticity in the OLS estimation at the average of the tax base, when also evaluated at the average tax rate weighted by the size of the tax base, is 0.17 . The implied elasticity by the IV estimation is 0.44 , which is higher compared to the baseline estimate, but not drastically. These results illustrate that our baseline results are robust to using alternative functional specifications commonly employed in empirical studies. It might be that, when our control set is partialled out, the remaining variation can be well approximated even by a linear in levels specification. 


\subsection{Controlling for a Spatial Heterogeneity in Resource Price Effects}

In our baseline estimations resource price effects are accounted for by the tax base dummies which are the interactions of the resource and the sector dummies. While it is possible to extend this strategy to account for the spatial variation in the resource or the sector specific effects by employing the interactions of country dummies with others, this introduces an enormous number of parameters to the model, and leads to a degrees of freedom problem.

Table 8: Controlling for Regional Resource Price Effects

Dependent Variable: $\log$ (Size of Tax Base in $\mathrm{CO}_{2}$ Emissions)

\begin{tabular}{lccccc}
\hline Estimator & OLS & \multicolumn{4}{c}{ Instrumental Variables } \\
\hline Weighting of Instrument & & $1 /$ Dist. & $1 /($ Dist. sq.) & $1 /($ Area $)$ & Pop. Dens. \\
& $(1)$ & $(2)$ & $(3)$ & $(4)$ & $(5)$ \\
\hline Tax & $-0.002^{* * *}$ & $-0.007^{* *}$ & $-0.005^{*}$ & -0.005 & $-0.006^{*}$ \\
& $(0.001)$ & $(0.003)$ & $(0.003)$ & $(0.003)$ & $(0.003)$ \\
\hline Adjusted $R^{2}$ & 0.801 & 0.781 & 0.784 & 0.784 & 0.783 \\
Observations & 343 & 268 & 268 & 268 & 268 \\
\hline First Stage Statistics & & & & & \\
Neighbours' Tax & & $0.285^{* * *}$ & $0.283^{* * *}$ & $0.256^{* *}$ & $0.260^{* * *}$ \\
& & $(0.075)$ & $(0.100)$ & $(0.105)$ & $(0.092)$ \\
Cragg-Donal Wald F stat. & & 13.565 & 11.184 & 9.952 & 11.288 \\
Kleibergen-Paap rk. Fstat. & & $14.458^{++}$ & $8.067^{+}$ & 5.963 & $7.982^{++}$ \\
\hline \hline
\end{tabular}

Notes: Robust standard errors clustered two-way by country and tax base (use-resource) dimensions are in parentheses. Significance of the coefficients is labeled as ${ }^{*} p<0.10$, ${ }^{* *} p<0.05,{ }^{* * *} p<0.01$. Rejection of maximal size bias, under $5 \%$ true rejection rate, indicated as ${ }^{+++} 10 \%,++15 \%,+20 \%$.

In this section, our aim is to control for the spatial variation in the resource prices. To this end, we extend our control set by interacting the resource dummies with region dummies which is motivated by the regional aspect of the resource markets. The regional classification of the countries is provided in the Appendix A. Hence, we avoid the degrees of freedom problem. The 
results are presented in Table (8) which are in line with the baseline results. In general, the coefficient estimates are slightly smaller and there is some loss of precision.

Table 9: Robustness Tests on Sampling

\begin{tabular}{lcccc}
\hline \hline \multicolumn{2}{l}{ Dependent Variable: $\log$ (Size of Tax Base in $\mathrm{CO}_{2}$ Emissions) } & & \\
\hline Deviations from baseline sample & Outliers & Waste\&Comb. & Off-Road & Full-Sample \\
& $(1)$ & $(2)$ & $(3)$ & $(4)$ \\
\hline Tax & $-0.006^{* * *}$ & -0.009 & $-0.008^{* * *}$ & -0.009 \\
& $(0.001)$ & $(0.006)$ & $(0.003)$ & $(0.006)$ \\
\hline Adjusted $R^{2}$ & 0.748 & 0.697 & 0.736 & 0.696 \\
Observations & 271 & 369 & 306 & 407 \\
\hline First Stage Statistics & & & & \\
Neighbours' Tax & $0.387^{* * *}$ & $0.353^{* * *}$ & $0.251^{* * *}$ & $0.338^{* * *}$ \\
& $(0.132)$ & $(0.110)$ & $(0.072)$ & $(0.110)$ \\
Cragg-Donal Wald F stat. & 6.576 & 19.994 & 11.620 & 19.414 \\
Kleibergen-Paap rk.Fstat. & $8.642^{+}$ & $10.235^{++}$ & $12.165^{++}$ & $9.483^{++}$ \\
\hline \hline
\end{tabular}

Notes: Robust standard errors clustered two-way by country and tax base (use-resource) dimensions are in parentheses. Significance of the coefficients is labeled as ${ }^{*} p<0.10$, ${ }^{* *} p<0.05,{ }^{* * *} p<0.01$. Rejection of maximal size bias, under $5 \%$ true rejection rate, indicated as ${ }^{+++} 10 \%,++15 \%,+20 \%$.

\subsection{Sampling}

Table (9) presents various robustness tests on our baseline estimation sample. Each column corresponds to the mentioned deviation from the baseline sample as described in the table, except the last column where we use the full sample. Our results are robust to inclusion of the outliers in regression (1) and the off-road transportation category in regression (3). However, incorporating the waste and combustibles category in regression (2) leads to a slightly higher effect and deteriorates the precision of the estimations (see the discussion in Section 2 for the potential reasons of such an outcome). In regression (4), we use the full sample. It can be seen that the results are similar to regression (2), 
and therefore likely to be driven by the inclusion of the waste and combustibles category. On the other hand, the first stage results are robust across all sample configurations.

\section{Concluding Remarks}

In this paper, we provide estimations of long-run effectiveness of a uniform carbon tax on energy consumption. We employ a unique dataset of the effective tax rates of the OECD countries that are calculated in terms of carbon dioxide emission which enables cross-sector and cross-resource comparison. The dataset accounts for the tax concessions which are prevalent in energy taxation, and therefore our results are not driven by the extra variation in the nominal tax rates. We argue that energy taxation is endogenous to energy consumption. As a remedy, we exploit the structure of our dataset in order to partial out resource and sector specific effects. Secondly, we document a positive correlation between the tax rates of neighboring countries which we use as our main identification strategy, and which is motivated by the strategic inter-governmental interaction theories under a immobile tax base assumption.

The predictions of the hypothesized effect by IV estimations are substantially larger than those predicted by the OLS estimations, indicating that energy taxes might be endogenous leading to a bias in the OLS estimations. The long-run implied elasticity by our preferred estimation strategy is 0.28 . This finding suggest that taxing the carbon content of three fossil fuel energy resources, namely coal, oil, and natural gas, can be an effective climate policy tool.

We conclude by highlighting a final remark about the presented analysis. Our econometric model imposes a rather strong assumption of homogeneity on the tax effects across the tax bases. The common approach in the literature is to work at a disaggregated level. However, this preference is driven not only by the heterogeneity of the tax bases but also its policy relevance and lack of a dataset that is appropriate to make a reliable comparison across the tax base categories. Moreover, our econometric model introduces some extra 
econometric difficulties that call for careful treatment, ie. the endogenous selection of tax base categories. However, carbon taxation is now a reality, and it is certainly relevant for an analysis of the entire energy tax base. Our dataset fulfills requirements of such an analysis by being comparable across the tax base categories in the energy sector. In addition, our econometric model allows for a limited type of heterogeneity via introducing tax base dummies which can account for the level of economic activity in each sector whether it is income or output. It should also be noted that, even in the studies conducted at the tax base level, the control sets are generally aggregate proxies. Unfortunately, we lack the means to test the homogeneity assumption. In particular, it is not possible to get precise estimates for each tax base category, since the number of observations per group is not sufficient. Despite this potential problem, we consider the presented results as relevant and important for the current policy debate. The mentioned difficulty above is related to the sample size. Therefore, we consider extending the coverage of this dataset crucial for future research. 


\section{References}

Acemoglu, D., Robinson, A., 2001. The colonial origins of comparative development: An empirical investigation. The American Economic Review 91 (5), 1369-1401.

Adda, J., Cornaglia, F., 2006. Taxes, cigarette consumption, and smoking intensity. The American Economic Review 96 (4), 1013-1028.

Alesina, A., Spolaore, E., 1997. On the number and size of nations. The Quarterly Journal of Economics 112 (4), 1027-1056.

Beck, T., Clarke, G., Groff, A., Keefer, P., Walsh, P., 2001. New tools in comparative political economy: The database of political institutions. The World Bank Economic Review 15 (1), 165-176.

Besley, B. T., Case, A., 1995. Incumbent Behavior : Vote-Seeking, Tax-Setting , and Yardstick Competition. The American Economic Review 85 (1), 25-45.

Brons, M., Nijkamp, P., Pels, E., Rietveld, P., 2008. A meta-analysis of the price elasticity of gasoline demand. a sur approach. Energy Economics 30 (5), 2105-2122.

Brueckner, J. K., 2003. Strategic Interaction Among Governments: An Overview of Empirical Studies. International Regional Science Review 26 (2), 175-188.

Case, A. C., Rosen, H. S., Hines, J. R., 1993. Budget spillovers and fiscal policy interdependence. Evidence from the states. Journal of Public Economics $52(3), 285-307$.

Coglianese, J., Davis, L. W., Kilian, L., Stock, J. H., 2016. Anticipation, tax avoidance, and the price elasticity of gasoline demand. Journal of Applied Econometrics Forthcoming.

Dahl, C., Sterner, T., 1991. Analysing gasoline demand elasticities: a survey. Energy Economics 13 (3), 203-210. 
Davis, L. W., Kilian, L., 2011. Estimating the effect of a gasoline tax on carbon emissions. Journal of Applied Econometrics 26 (7), 1187-1214.

Devereux, M. P., Lockwood, B., Redoano, M., 2007. Horizontal and vertical indirect tax competition: Theory and some evidence from the USA. Journal of Public Economics 91 (3-4), 451-479.

Devereux, M. P., Loretz, S., 2013. What do we know about corporate tax competition? National Tax Journal 66 (3), 745-774.

Ekins, P., Speck, S., 1999. Competitiveness and exemptions from environmental taxes in europe. Environmental and Resource Economics 13 (4), 369-396.

Espey, M., 1998. Gasoline demand revisited: an international meta-analysis of elasticities. Energy Economics 20 (3), 273-295.

Evers, M., De Mooij, R. A., Vollebergh, H. R., 2004. Competition under minimum rates: The case of european diesel excises. CESifo Working Paper No: 1221.

Fredriksson, P. G., Millimet, D. L., 2002. Strategic Interaction and the Determination of Environmental Policy across U.S. States. Journal of Urban Economics 51 (1), 101-122.

IEA, 2011. Energy balances of oecd countries. OECD Publishing, Paris.

IEA, 2016. Energy Prices and Taxes. Vol. 2016/2, Paris. International Energy Agency.

Keen, M., Konrad, K. A., 2013. The theory of international tax competition and coordination. Handbook of Public Economics 5, 257.

Li, S., Linn, J., Muehlegger, E., 2014. Gasoline taxes and consumer behavior. American Economic Journal: Economic Policy 6 (4), 302-42.

Lin, B., Li, X., 2011. The effect of carbon tax on per capita $\mathrm{CO}_{2}$ emissions. Energy Policy 39 (9), 5137-5146. 
Mankiw, N. G., Weinzierl, M., Yagan, D., 2009. Optimal taxation in theory and practice. Tech. rep., National Bureau of Economic Research.

Martin, R., de Preux, L. B., Wagner, U. J., 2014. The impact of a carbon tax on manufacturing: Evidence from microdata. Journal of Public Economics $117,1-14$.

Metcalf, G. E., 2009. Designing a carbon tax to reduce us greenhouse gas emissions. Review of Environmental Economics and Policy 3 (1), 63-83.

Milesi-Ferretti, G. M., Perotti, R., Rostagno, M., 2002. Electoral systems and public spending. Quarterly Journal of Economics, 609-657.

Murdoch, J. C., Sandler, T., Sargent, K., 1997. A Tale of Two Collectives: Sulphur versus Nitrogen Oxides Emission Reductioni in Europe. Economica 64, 281-301.

Nordhaus, W. D., 1977. The demand for energy: an international perspective.

OECD, 2013a. Inventory of estimated budgetary support and tax expenditures for fossil fuels. OECD Publishing, Paris.

OECD, 2013b. Taxing energy use: A graphical analysis. OECD Publishing, Paris.

Parry, I. W., Norregaard, J., Heine, D., 2012. Environmental tax reform: principles from theory and practice. Annual Review of Resource Economics 4 (1), $101-125$.

Persson, T., Roland, G., Tabellini, G., 2000. Comparative politics and public finance. Journal of Political Economy 108 (6), 1121-1161.

Revelli, F., 2005. On spatial public finance empirics. International Tax and Public Finance 12 (4), 475-492.

Rivers, N., Schaufele, B., 2015. Salience of carbon taxes in the gasoline market. Journal of Environmental Economics and Management 74, 23-36. 
Schmalensee, R., Stoker, T. M., 1999. Household Gasoline Demand in the United States. Econometrica 67 (3), 645-662.

Surrey, S. S., 1985. Tax expenditures. Harvard University Press.

Vollebergh, H., 2012. Environmental taxes and green growth. Tech. Rep. 1019, PBL Netherlands Environmental Assessment Agency.

Weitzman, M. L., 2016. How a minimum carbon price commitment might help to internalize the global warming externality. Tech. rep., National Bureau of Economic Research.

Wooldridge, J. M., 2010. Econometric analysis of cross section and panel data. MIT press.

Yatchew, A., No, J. A., 2001. Household gasoline demand in Canada. Econometrica 69 (6), 1697-1709. 


\section{Appendices}

\section{A More on the Dataset}

In this data appendix, we provide further details about our dataset.

Tax expenditures: Here, we illustrate the importance of using effective tax rates rather than nominal rates which does not account for the tax deductions prevalent in the energy taxation of the OECD countries. Figure (1) presents the country level tax expenditure ratios, which is the ratio of the foregone revenue via tax concessions to the total potential tax revenue, for some selected ranges of this ratio. Sweden has the highest ratio which is 0.4, and Estonia has the lowest non-zero value. It can be seen that the variation across countries is rather high. Furthermore, the size of the tax expenditures is substantial. Hence ignoring this aspect of energy taxation can lead to misleading results, as this variation also stems from the subjective judgments in the tax codes about the benchmark tax rates.

Distributional properties: Figure 2 illustrates the distribution of the size of the tax base across countries for each specific tax base category. Figure 3 illustrates the same information for the tax levels. In order to illustrate the variation in the tax levels clearly, we use logarithm of the tax rates, while in our baseline specification we do not apply any transformation to the tax variable for the reasons explained in Section 5.4.

Country list: The list of countries in our dataset is provided in Table 10. The table also documents the regional classification of these countries in the estimations in Section 5.5. In the IV estimations, the island countries (Japan, United Kingdom, Australia, Iceland) are excluded, since they do not have any contiguous neighbors, and hence are assigned zero weights in the strategic interaction equations. 
Figure 1: Tax Expenditures in Total Potential Revenue

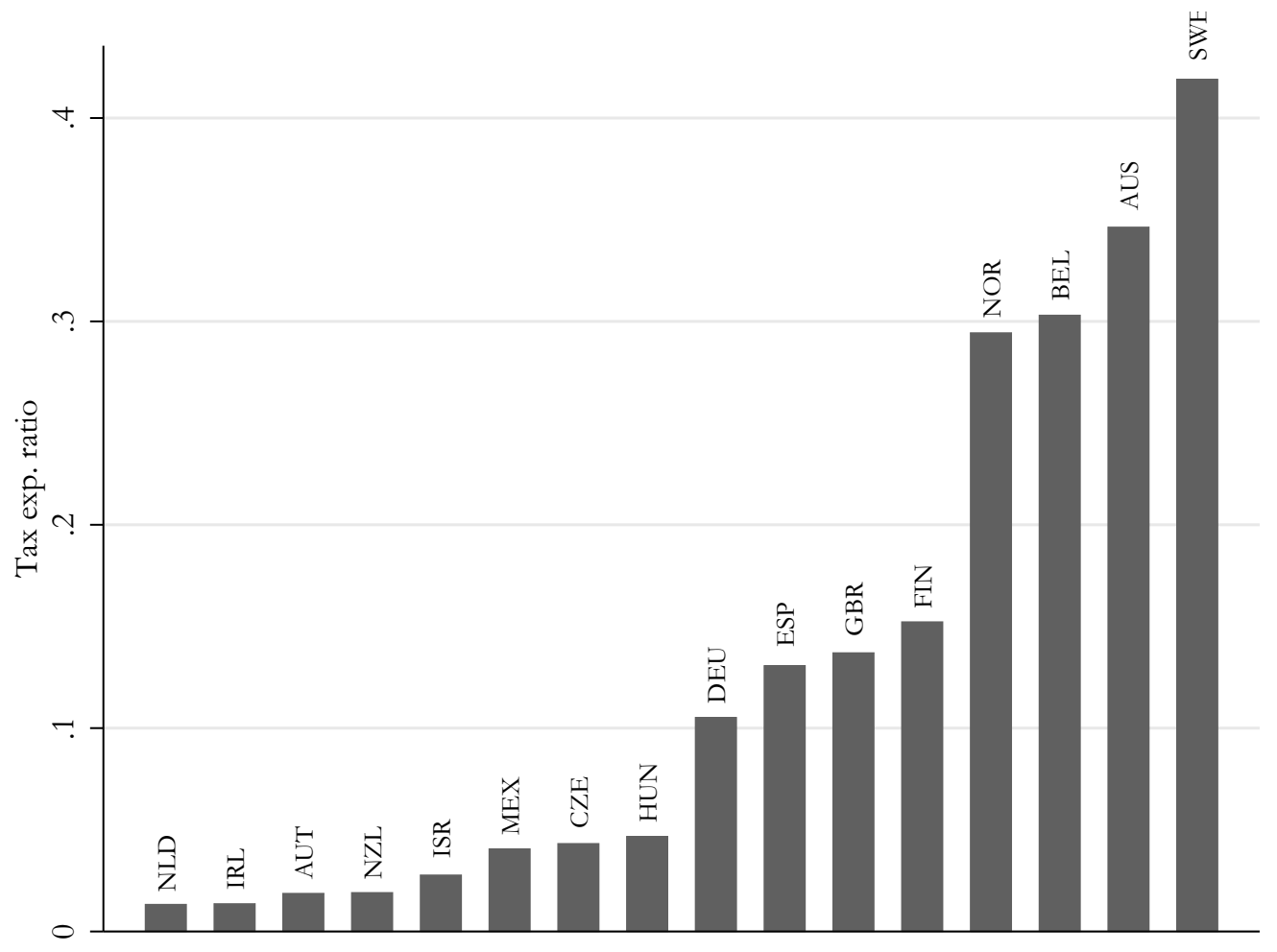

Explanation: This figure illustrates the tax expenditures ratios across countries. Tax expenditure ratio is defined as the ratio of forgone revenues through tax expenditures to the total potential revenues. 
Figure 2: Distribution of the Size of the Tax Base

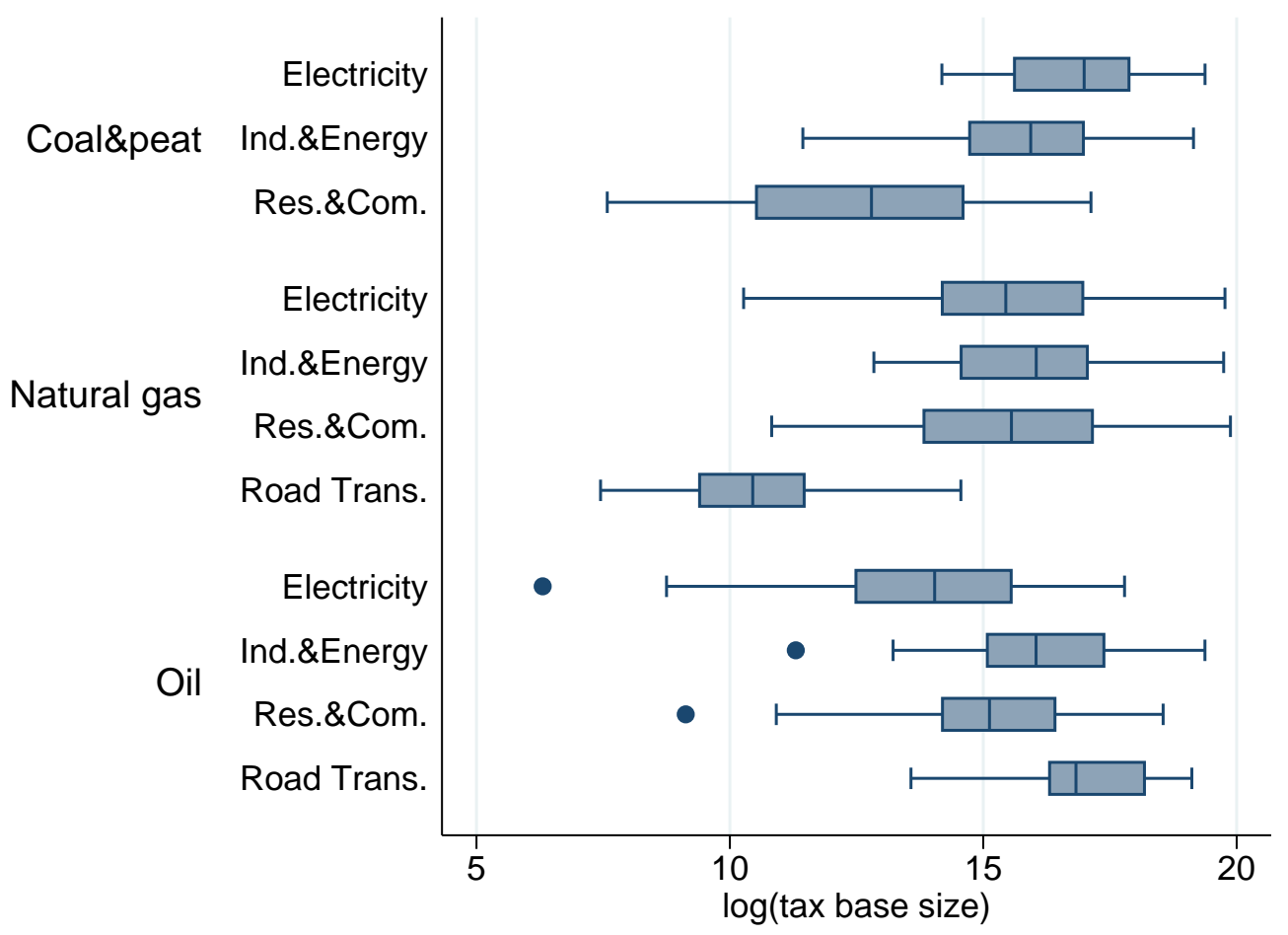

Explanation: This figure illustrates the distribution of the size of the tax base across countries for each tax base category. Each box-plot indicates the median, upper and lower $25^{\text {th }}$ percentiles, and the adjacent values which determines the outliers indicated with dots. 
Figure 3: Distribution of the Tax Rates

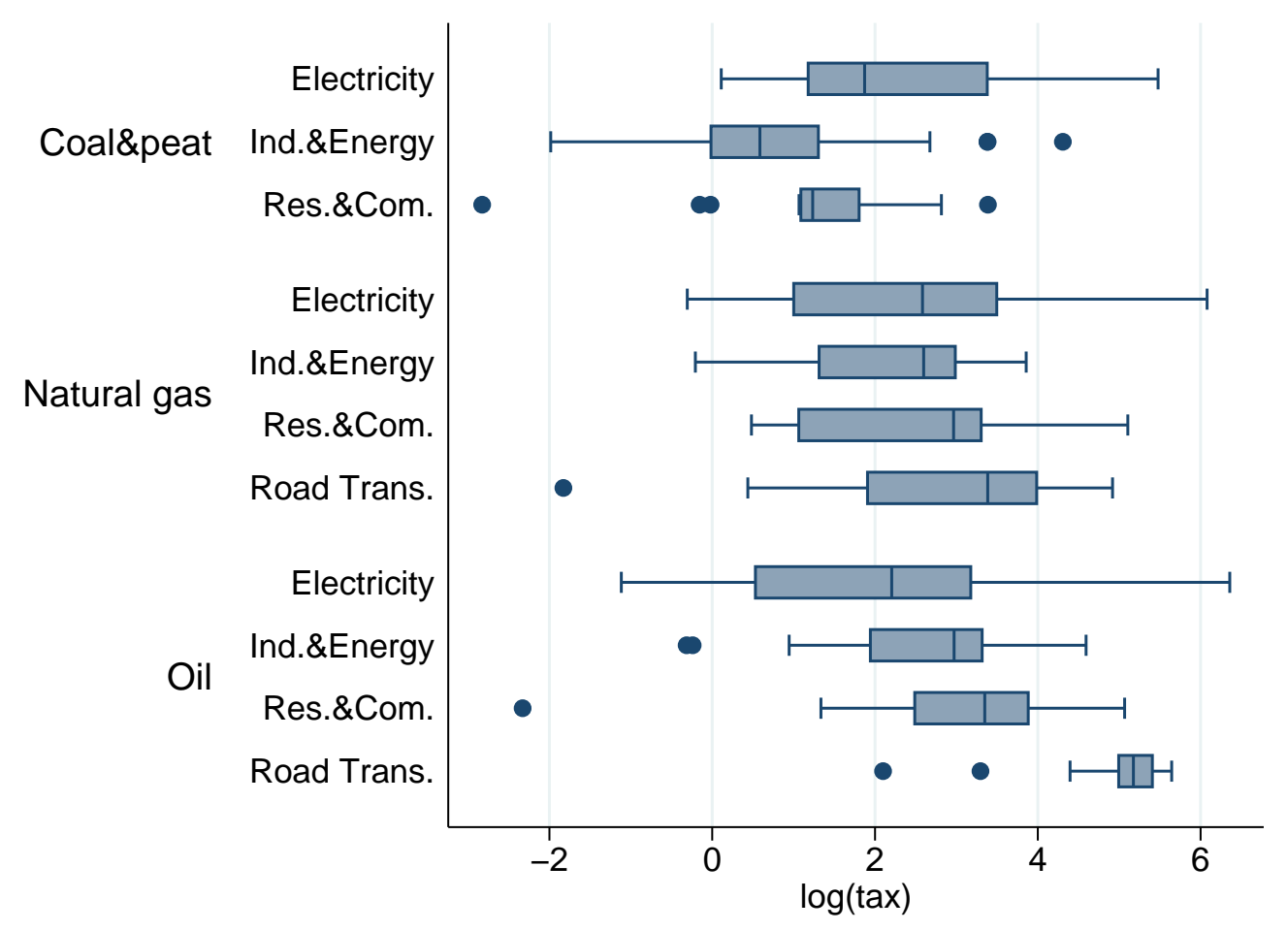

Explanation: This figure illustrates the distribution of tax rates across countries for each tax base category. Each box-plot indicates the median, upper and lower $25^{\text {th }}$ percentiles, and the adjacent values which determines the outliers indicated with dots. 
Table 10: List of Countries and Regions

\begin{tabular}{llll}
\hline Countries & Regions & Countries & Regions \\
\hline Australia & Asia-Pacific & Finland & Scandinavia \\
Japan & Asia-Pacific & Iceland & Scandinavia \\
Korea, Republic Of & Asia-Pacific & Norway & Scandinavia \\
New Zealand & Asia-Pacific & Sweden & Scandinavia \\
Czech Republic & Central and Eastern Europe & Austria & Western Europe \\
Estonia & Central and Eastern Europe & Belgium & Western Europe \\
Hungary & Central and Eastern Europe & France & Western Europe \\
Poland & Central and Eastern Europe & Germany & Western Europe \\
Slovakia & Central and Eastern Europe & Greece & Western Europe \\
Slovenia & Central and Eastern Europe & Ireland & Western Europe \\
Israel & Middle East & Italy & Western Europe \\
Turkey & Middle East & Luxembourg & Western Europe \\
Canada & North America & Netherlands & Western Europe \\
Mexico & North America & Portugal & Western Europe \\
United States & North America & Spain & Western Europe \\
Chile & South America & Switzerland & Western Europe \\
Denmark & Scandinavia & United Kingdom & Western Europe \\
\hline & & & \\
\hline
\end{tabular}

